\title{
Post- Impact Fatigue Damage Analysis of Quasi Isotropic CFRP Laminates through Infrared Thermography
}

\author{
Raghu V. Prakash, Mathew John \\ Indian Institute of Technology Madras, Chennai, Tamil Nadu 600 036, India \\ raghuprakash@iitm.ac.in,.bttp://orcid.org/0000-0002-8888-022X \\ mathewjon18@gmail.com,bttp://orcid.org/0000-0001-8504-7016
}

\begin{abstract}
Carbon fiber reinforced plastic (CFRP), widely used in aircraft structures is susceptible to accidental low velocity impacts during manufacture or while in service. The damage due to impact, though small initially, can progress due to fatigue loading to cause final fracture. In this study, the CFRP laminates subjected to three different energy levels of low velocity impact were tested under constant amplitude and aircraft fatigue spectrum loading conditions till it reached the failure state. The infrared thermography NDT technique was used to understand the damage distribution across the specimen after fatigue loading of impacted specimens. The cooling response curve of specimens was obtained by the active thermography technique for different experimental conditions, namely, heat transfer by the transmission or reflection mode and impacted or un-impacted surface facing camera. The cooling response obtained when the impact damage as well as heating was on the rear surface provided a good correlation with the damage volume quantified through $\mathrm{X}$-ray $\mathrm{CT}$ image processing. The temperature rise observed by passive thermography technique at the fiber/ply breakage during static residual strength tests was found to be proportional to the load drop and extent of pre-existing damage.
\end{abstract}

KEYwORDs. CFRP; Low velocity impact; Fatigue; Damage; Thermography; $\mathrm{X}$-ray CT.

\section{OPEN@ACCESS}

Citation: Prakash, R., V., John, M., PostImpact Fatigue Damage Analysis of Quasi Isotropic CFRP Laminates through Infrared Thermography, Frattura ed Integrità Strutturale, 49 (2019) 536-546.

Received: 07.01.2019

Accepted: 03.04.2019

Published: 01.07.2019

Copyright: (C) 2019 This is an open access article under the terms of the CC-BY 4.0, which permits unrestricted use, distribution, and reproduction in any medium, provided the original author and source are credited.

\section{INTRODUCTION}

$\mathrm{P}$ erformance under fatigue loading is one of the important criteria for qualification of fiber reinforced composite materials that are used in aircraft industries. One of the disadvantages associated with the use of Carbon Fiber Reinforced Plastic (CFRP) materials is - its performance under fatigue loading conditions gets affected even when it contains barely visible impact damage (BVID) caused by low velocity accidental impacts, such as tool drop, hail storm. The BVID grows in size during subsequent fatigue loading to cause failure of the component. As the defect is barely 
visible, effective in-situ NDT methods are important; equally important is the need to understand damage progression in such materials under fatigue loading for effective life prediction [1].

In order to provide practical information on the damage state of FRP composite materials, a number of non-destructive methods that are well-established can be employed [2-4]. The use of full field non-contact measurement technique, such as, the infrared thermography (IRT) for the in-situ detection of fatigue damage in materials has recently been established as a valid non-destructive evaluation (NDE) technique. It is based on the fact that fatigue damage is an energy dissipative process that is accompanied by the temperature variation. The measurement of temperature variation during mechanical loading is referred to as passive thermography as no external thermal activation is provided to the specimen. If an external heating is invoked and the temperature variation with time is studied, it is referred to as active thermography.

John Montesano et al. (2013) conducted fatigue studies on carbon fiber-polyimide resin composite and stated that the high cycle fatigue strength determined using the thermographic approach showed excellent correlation with that of conventional stress-life curve. The authors state that IRT is quite successful in detecting damage initiation and growth; hence, it is an effective technique for assessing the fatigue damage progression in components made of composite materials [5].

Kristine M. Jespersen et al. (2016) used multi-scale 3-D X-ray Computed Tomography (CT) technique for understanding the damage evolution under tension-tension fatigue loading for a uni-directional (UD) composite made from a noncrimped glass fiber fabric used for wind turbine blades. They noted that 3-D tomography technique can be used to detect certain damages, which cannot be determined from 2-D destructive analyses [6]. The recent advances in the X-ray CT aid the researchers in detecting and characterizing damages in the fiber reinforced composite materials in the three dimensions $[7,8]$. In this study, the post-impact, post-fatigue damage is evaluated using active IR thermography and the cooling response is compared with damage quantified through X-ray CT images as well as with the loss in stiffness of the specimens due to the impact and fatigue loading.

\section{EXPERIMENTAL METHODOLOGY}

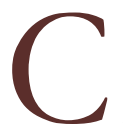

FRP laminates of size $300 \mathrm{~mm} \times 300 \mathrm{~mm}$ with $4.5 \mathrm{~mm}$ thickness were prepared by the hand layup process coupled with compression molding technique using carbon woven roving mat as reinforcement and epoxy as the matrix with the quasi-isotropic stacking sequence of $[0 \# 90, \pm 45,0 \# 90, \pm 45] \mathrm{s}$. The carbon fiber mat with density of $480 \mathrm{~g} / \mathrm{m}^{2}(\mathrm{gsm})$ had 90 numbers of yarns for $300 \mathrm{~mm}$ of length and which is equal in both warp and weft directions. The carbon fiber had a tensile strength of $3450 \mathrm{MPa}$ and a co-efficient of thermal expansion of $-0.4 \mu \mathrm{m} / \mathrm{m} /{ }^{\circ} \mathrm{C}$. A commercially available Araldite ${ }^{\circledR}$ LY556 (an unmodified liquid epoxy resin based on Bisphenol-A) is chosen as matrix and the curing agent is Aradur ${ }^{\circledR}$ HY951 (an unmodified aliphatic polyamine - tri-ethylene tetra amine). The specific gravity of the carbon fiber and the epoxy resin used for the study are 1.8 and 1.3 respectively. It may be noted that this resin in general, provides high stiffness and strength to the CFRP laminate, but, it often behaves in an undesirably brittle manner when the plastic deformation is constrained, like for example, an impact loading.

The tensile specimens as per the ASTM 3039 standard having a nominal dimension of $25 \mathrm{~mm}$ x $250 \mathrm{~mm}$ were extracted from the laminate. The fatigue specimens having nominal dimensions of $45 \mathrm{~mm} \times 250 \mathrm{~mm}$ as well as ones with reduced width of $35 \mathrm{~mm}$ at the hour-glass section were cut using a CNC router. The use of hour-glass specimen ensures concentration of damage and stress at the central region of the specimen during loading. Fig. 1 presents the photograph of one such CFRP laminate prepared and some of the specimens prepared thereafter from the laminate.

The tensile and fatigue tests were conducted using a $100 \mathrm{kN}$ MTS servo-hydraulic testing machine. Prior to fatigue testing, the tensile tests as per ASTM D 3039 standard were conducted on un-impacted and $35 \mathrm{~J}$ impacted laminate specimens for determining the load range for the fatigue cycling. The static strength tests for the un-impacted and post-impact and postfatigue specimens were conducted with a constant cross head speed of $2 \mathrm{~mm} / \mathrm{min}$. The eight layer quasi-isotropic specimen had an ultimate tensile strength of $337 \mathrm{MPa}$ (with a standard deviation of $16.5 \mathrm{MPa}$ and coefficient of variation of $4.9 \%$ ) and a tensile modulus of $42.53 \mathrm{GPa}$. The tensile strength for a $35 \mathrm{~J}$ impacted quasi-isotropic CFRP specimen reduced to $126 \mathrm{MPa}$.

The fatigue specimens were impacted with drop weight impactor to three different energy levels of $23 \mathrm{~J}, 35 \mathrm{~J}$ and $51 \mathrm{~J}$. Fatigue tests were then conducted under: a) constant amplitude (CA) load cycling with the maximum load of $8.82 \mathrm{kN}$ and the minimum load of $0.882 \mathrm{kN}$ (thus, at a stress ratio of 0.1 ), and b) under programmed-FALSTAFF spectrum loading [911] which is a variable amplitude (VA) with the maximum load of $8.82 \mathrm{kN}$. The programmed- FALSTAFF spectrum represents 200 flights of an European Standard fighter aircraft fatigue loading and consists of 1242 cycles in total which includes 18 major cycles. The balance, 1224 cycles are divided into 18 identical blocks called as marker blocks (minor 
loads) each having 68 cycles. The details of programmed FALSTAFF spectrum can be found in Ref. 9. The minor loads when applied in the ascending order of load amplitude (low-to high), the VA loading is designated as Lo-Hi and when applied in the descending order of high to low ranges of load during VA loading, it is designated as Hi-Lo. Both Lo-Hi and Hi-Lo versions of VA loading were applied during fatigue testing to understand the effect of load sequence on the quasi-isotropic composite laminates. The tensile tests were carried out after fatigue cycling to estimate the residual strength of the laminate after post-impact, post-fatigue load conditions; during the residual strength tests, passive infrared thermography technique was employed to understand the thermal emissivity of the specimen during failure events.

The IR thermography tests were carried out using a Micro-Epsilon make IR camera (TIM 160) having a spectral range of 7.6 to $13 \mu \mathrm{m}$ and an optical resolution of $160 \times 160$ pixels at a scan rate of $120 \mathrm{~Hz}$. The thermo-mechanical response of CFRP specimens during the static strength tests was recorded using passive thermography technique, with a pre-set emissivity value of 0.9 . In the case of active thermography, the photo-thermal heating on one side of the specimens was done by using a $1000 \mathrm{~W}$ halogen lamp as external heating source for a short period of 20 seconds such that the heated specimen surface attains a maximum temperature (say $85^{\circ} \mathrm{C}$ ). This was done under four different combinations of either keeping the impact surface at back (ISB) or impact surface at front (ISF) and by either heating the surface from the rear surface while monitoring the temperature on the front face or by heating the surface from the front surface and measuring the temperature variation from the front side. Heating the specimen from the rear surface (HB) while monitoring the temperature on the front surface implies that the heat has to transmit through the specimen thickness, hence referred to as transmission mode; while heating from the front surface (HF) and measuring from front surface is designated as reflection mode of active thermography. One such arrangement of ISB HB is schematically shown in Fig. 1(c). The temperature response with respect to time of the specimens was monitored until it reached the room temperature after the thermal activation. Tab. 1 summarizes the different mechanical and IR thermography experiments conducted as part of this study. The end-state damage condition was examined in a qualitative and quantitative manner by employing the 3D $\mathrm{X}$-ray CT images. The CT scanning of the specimens were carried out using a GE Pheonix v-tome-x model CT system $(240 \mathrm{kV}, 320 \mathrm{~W}$ directional X-ray tube) with the set parameters of $50 \mathrm{kV}$ voltage, $100 \mu \mathrm{A}$ current and an integration time 333 ms with $75 \mu \mathrm{m}$ resolution.

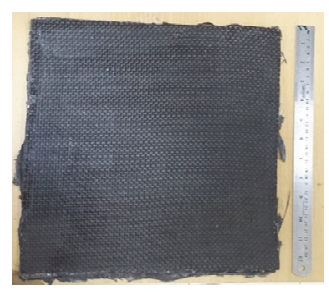

(a)

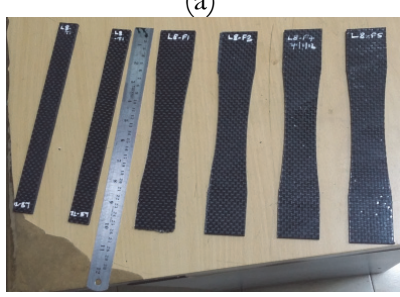

(b)

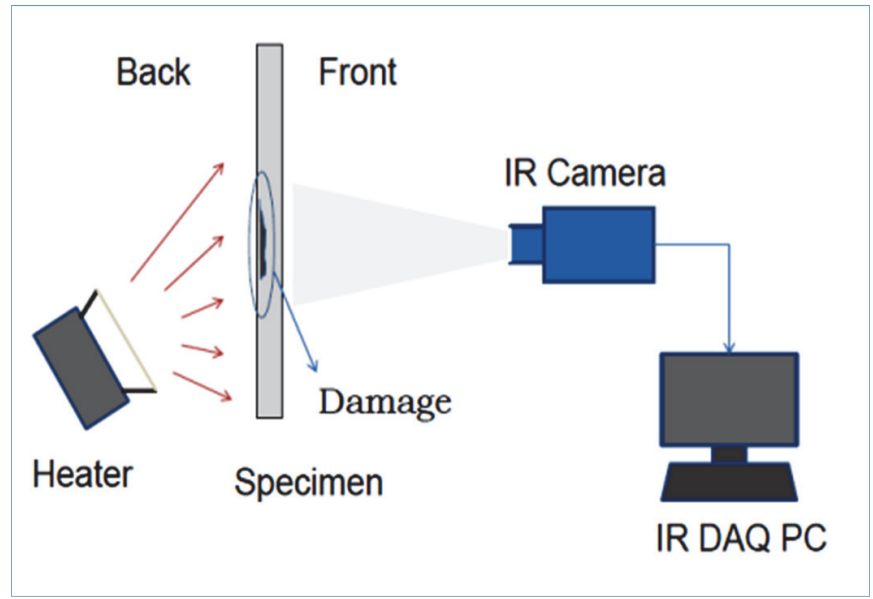

(c)

Figure 1: (a) The photograph of CFRP laminate; (b) The tensile and fatigue specimens; (c) Schematic diagram of thermography for the configuration - impact surface at back- heating from back (ISB-HB).

\section{RESULTS AND DISCUSSION}

\section{Residual strength}

7 he residual strength of the impacted $(23 \mathrm{~J}, 35 \mathrm{~J}$ or $51 \mathrm{~J}$ ) and fatigue loaded (CA or Prog-FALSTAFF Lo Hi / HiLo) specimens was determined through the tensile tests and compared with that of the un-impacted specimens.

The force-displacement response is shown in Fig. 2(a) and the stiffness estimated for the initial stage of loading (10\%-50\% window) from the tensile test is shown in Fig. 2 (b). The final damage state of all the post-impacted fatigue 
cycled specimens was quantified through the image processing of the planar section 2D X-ray CT images before the tensile tests. The intra-laminar damage which is mainly responsible for the strength or stiffness reduction due to impact and subsequent fatigue loading, is measured and quantified in terms of damage volume through the average area method. Details of damage quantification by average area method are available in Ref. 12. Tab. 2 presents the results of stiffness reduction and damage volume fraction estimated for various specimens. It can be seen that the stiffness at the end state of the tested specimens is proportional to the extent of impact and the fatigue loading which is estimated through damage volume. In one case (23 J Lo-Hi) the residual strength is not proportional to the damage contained in the specimen. The reason for that could be the multiple major ply breaks that happened in this case as seen in F-d diagram (Fig. 2 (a)) as well as observed through the passive thermography (to be discussed in the later section - also Fig. 5). Earlier studies on this test case suggested that there is a minimum threshold in impact damage that can cause damage progression during fatigue and $23 \mathrm{~J}$ happens to be on the threshold level of impact damage.

\begin{tabular}{|c|c|c|c|c|}
\hline $\begin{array}{l}\text { Sl. } \\
\text { No. }\end{array}$ & $\begin{array}{l}\text { Specimen Impact } \\
\text { Condition }\end{array}$ & Fatigue & Passive Thermograhy & $\begin{array}{l}\text { Active Thermograhy } \\
\text { (for all the four experimental } \\
\text { configurations) }\end{array}$ \\
\hline 1 & Pristine & \multirow{4}{*}{$\begin{array}{l}\text { CA, VA (Lo-Hi) } \\
\text { VA (Lo-Hi and Hi- } \\
\text { Lo) } \\
\text { VA (Lo-Hi and Hi- } \\
\text { Lo) }\end{array}$} & \multirow{4}{*}{$\begin{array}{l}\text { Carried out for all the } \\
\text { specimens during } \\
\text { static tensile tests. }\end{array}$} & Done \\
\hline 2 & $23 \mathrm{~J}$ Impacted & & & - \\
\hline 3 & $35 \mathrm{~J}$ Impacted & & & $\begin{array}{c}\text { Done for both Lo-Hi and } \\
\text { Hi-Lo }\end{array}$ \\
\hline 4 & $51 \mathrm{~J}$ Impacted & & & Done for Lo-Hi \\
\hline
\end{tabular}

Table 1: Test matrix for mechanical and IR thermography experiments.

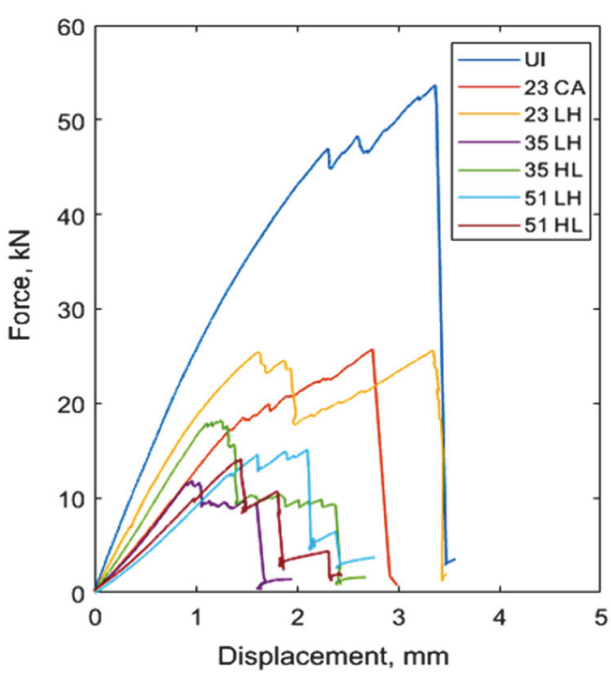

(a)

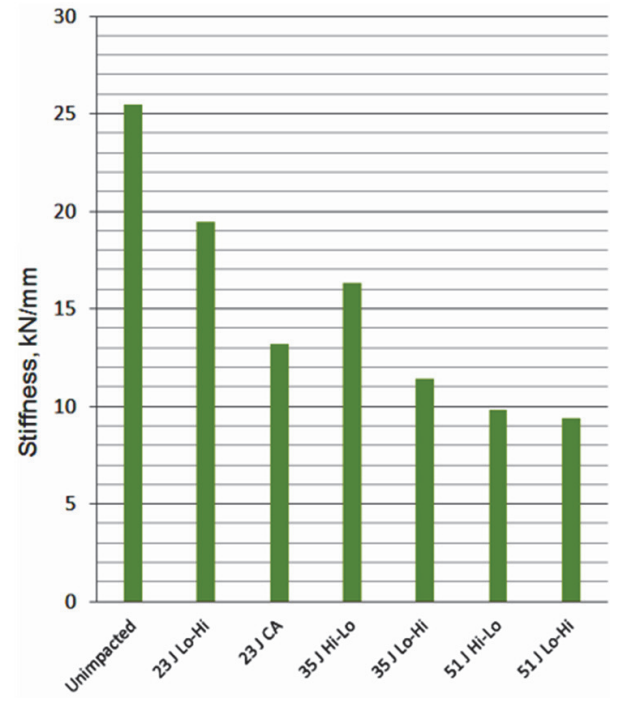

(b)

Figure 2: (a) The load-displacement diagram of the specimens during tensile test; and (b) The stiffness estimated for the pristine as well as post-impacted fatigue loaded specimens from the tensile test.

\section{Infrared Thermography - Passive thermography}

The change in temperature of the specimen due to the mechanical loading (referred to as thermo-mechanical response) was captured online by the IR camera during the tensile loading for the un-impacted specimens as well as post-impact, post-fatigue specimens. The temperature variation due to thermo-mechanical effect during tensile loading at three area segments (A1, A2 and A3) of equal sizes $24 \mathrm{~mm} \times 34 \mathrm{~mm}$ each for the pristine tensile specimen of $25 \mathrm{~mm}$ uniform width is plotted in Fig. 3 (a). For the impacted specimens, three area segments (A1, A2 and A3) of equal size $24 \mathrm{~mm} \times 34 \mathrm{~mm}$ (width of hour glass specimen at critical section) were chosen for temperature measurements. The temperature increase was significant for unimpacted specimen as seen in Fig. 3(a) while the temperature variation was relatively small in the case of post-impact, post-fatigue cycled specimens. Further, the thermo-elastic response (where the tensile loading in 
elastic regime causes cooling of the specimen) of the CFRP specimens is not significant when compared to GFRP [13] or metallic materials as the carbon fibers have negative coefficient of thermal expansion.

\begin{tabular}{|c|c|c|c|c|c|}
\hline S. No & $\begin{array}{l}\text { Input Impact } \\
\text { Energy (J) }\end{array}$ & $\begin{array}{l}\text { Fatigue Test } \\
\text { Condition }\end{array}$ & $\begin{array}{l}\text { Residual Strength } \\
\qquad(\mathrm{kN})\end{array}$ & \% Loss in Stiffness* & $\begin{array}{c}\% \text { Damage Volume } \\
\text { Fraction }\end{array}$ \\
\hline 1 & Un-impacted & - & 53.67 & - & $<0.5$ \\
\hline 1 & $23 \mathrm{~J}$ & Constant Amplitude & 53.67 & 30.20 & 4.83 \\
\hline 2 & $23 \mathrm{~J}$ & $\begin{array}{l}\text { Lo-Hi Prog } \\
\text { FALSTAFF }\end{array}$ & $\begin{array}{l}\text { Specimen failed } \\
\text { in fatigue }\end{array}$ & 5.92 & 1.88 \\
\hline 3 & $35 \mathrm{~J}$ & $\begin{array}{l}\text { Hi-Lo Prog } \\
\text { FALSTAFF }\end{array}$ & 18.18 & 26.72 & 3.77 \\
\hline 4 & $35 \mathrm{~J}$ & $\begin{array}{l}\text { Lo-Hi Prog } \\
\text { FALSTAFF }\end{array}$ & 11.83 & 37.64 & 4.09 \\
\hline 5 & $51 \mathrm{~J}$ & $\begin{array}{l}\text { Hi-Lo Prog } \\
\text { FALSTAFF }\end{array}$ & $\begin{array}{l}\text { Specimen failed } \\
\text { in fatigue }\end{array}$ & 52.59 & 5.60 \\
\hline 6 & $51 \mathrm{~J}$ & $\begin{array}{l}\text { Lo-Hi Prog } \\
\text { FALSTAFF }\end{array}$ & 15.14 & 55.51 & 7.92 \\
\hline
\end{tabular}

Table 2: The damage volume fraction of post-impacted specimens Vs. loss in stiffness.

Fig. 3 (b) presents the plot of average temperature observed for the three area segments during tensile loading. It is noted that the highest temperature of $54.3^{\circ} \mathrm{C}$ is seen in area A1, followed by area $\mathrm{A} 2\left(42.4^{\circ} \mathrm{C}\right)$ and subsequently by area A3 $(39.2$ $\left.{ }^{\circ} \mathrm{C}\right)$. This peak temperature corresponds to specimen failure at the peak load. However, it is interesting to note that the temperature-time response for area A3 alone shows some spikes at $\sim 70$ seconds and once again at $\sim 90$ seconds) which was not seen in temperature response in other two areas of measurement. To verify if this has some correlation to damage progression, data of force-time response and temperature-time response was plotted.

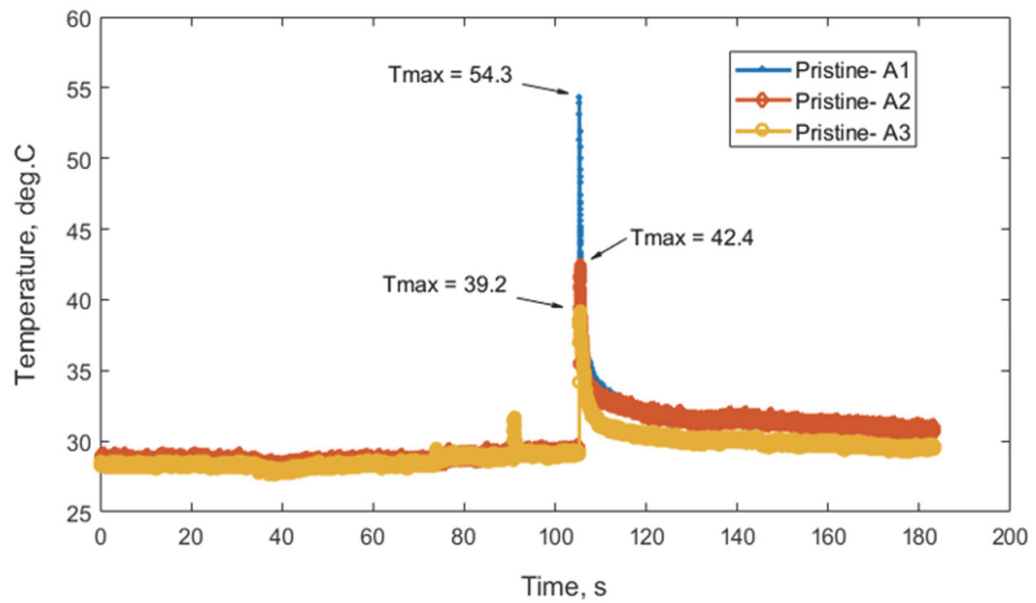

(a)

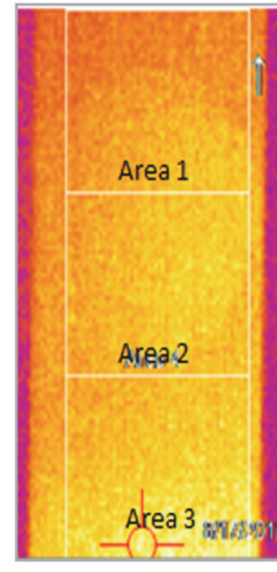

(b)

Figure 3: (a) The temperature variation within the pristine specimen during the tensile test; (b) The position of area segments A1, A2 and A3 marked in a specimen under no load condition.

Fig. 4 presents the correlation between temperature rise and tensile load during two ply-drop failures. The ply-drop failures in area A3 have resulted in fiber-matrix debonding and fiber breakage, and as a consequence, the final failure of 
the specimen in this region happened with reduced energy levels. Further, the heat flux in the specimen does not pass it on to the surface, hence the peak temperature rise in region A3 could be less. However, in regions A1 and A2, where there was no indication of ply-failures, the energy absorbed by the specimen was relatively high, which resulted in higher temperatures at the time of final tensile fracture. Based on the above, one can say that a good correlation between failure events (as inferred through F-d plots) and temperature evolution exists. Thermal imaging technique could identify the onset of damage initiation as well as non-homogenous damage distribution across the gage length of the specimen.

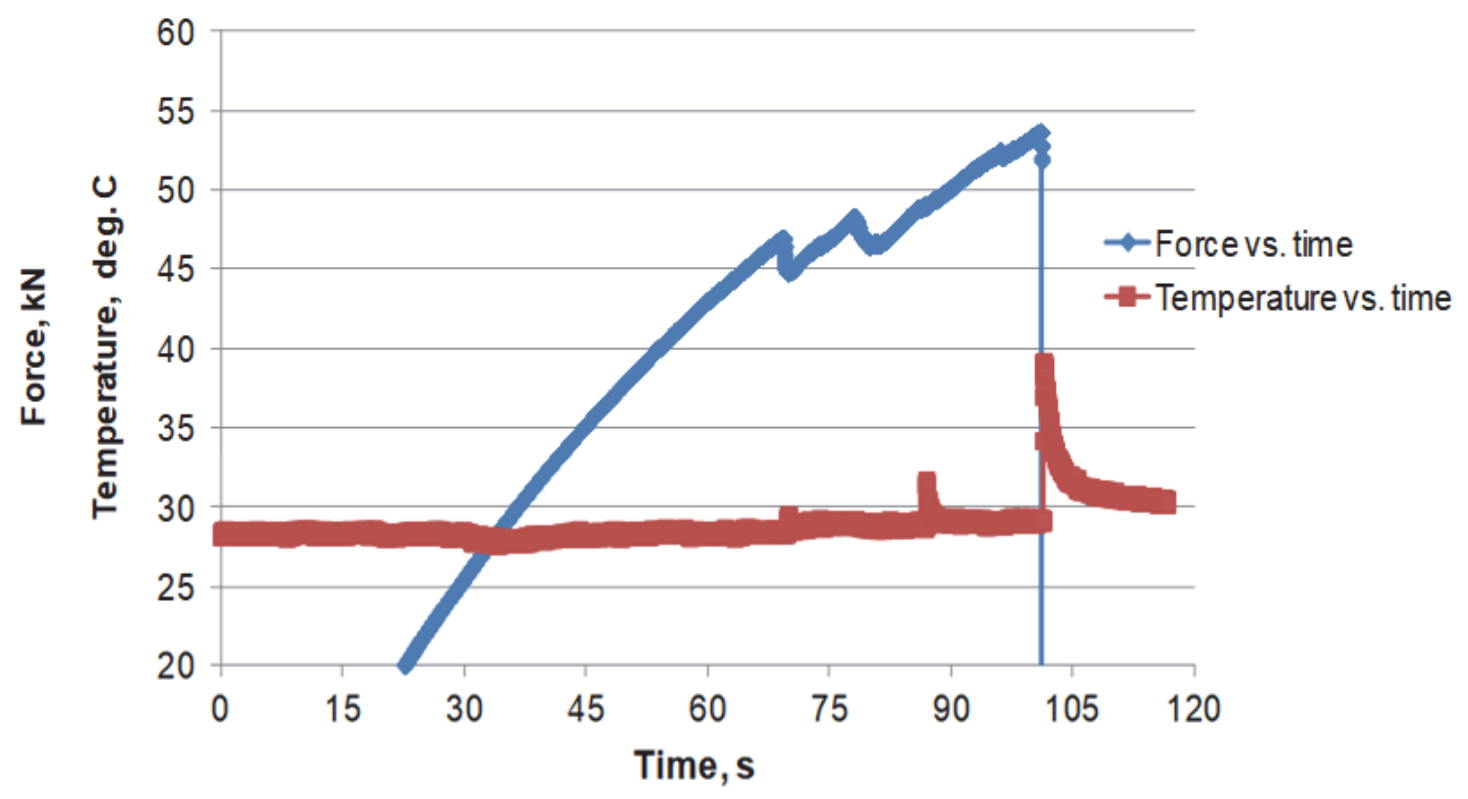

Figure 4: The composite graph of Force vs. time and Temperature vs. time for the un-impacted specimen (the temperature response at the bottom segment (A3) is plotted).

The temperature response during static strength tests of post-impact post-fatigue specimens is shown in Figs. 5 and 6 . It may be noted that the presence of matrix cracks and minor delaminations in the specimen in the case of impact, fatigue damaged specimens could obstruct the passage of heat flux to surface from the bulk of the specimen. As a consequence, the temperature rise during tensile pull-out tests is not as significant in impacted specimens compared to the previous case of un-impacted tensile specimen. The peak temperature response at the onset of failure of the material is indicative of the failure mode. Between impacted specimens of different impact energy levels, the temperature rise at failure is not significant except for $23 \mathrm{~J} \mathrm{CA}$ (flat) and $23 \mathrm{~J} \mathrm{Lo-Hi} \mathrm{specimens.} \mathrm{This} \mathrm{could} \mathrm{be} \mathrm{due} \mathrm{to} \mathrm{reduced} \mathrm{levels} \mathrm{of} \mathrm{damage} \mathrm{caused} \mathrm{to}$ the specimen by $23 \mathrm{~J}$ impact. In the case of $23 \mathrm{~J}$ CA hour glass specimens the entire impact damage and subsequent fatigue damage was concentrated at the middle minimum width $(35 \mathrm{~mm})$ region and hence the minimum temperature rise is seen (ref. Fig. 5). In the case of $23 \mathrm{~J} \mathrm{Lo-Hi,} \mathrm{the} \mathrm{multiple} \mathrm{major} \mathrm{peaks} \mathrm{in} \mathrm{the} \mathrm{temperature} \mathrm{profile} \mathrm{can} \mathrm{be} \mathrm{seen} \mathrm{as} \mathrm{the} \mathrm{load}$ drop (ply failure) occurs in two major steps as seen in the force-displacement curve [see Fig. 2 (a) for legend $23 \mathrm{~J} \mathrm{LH]}$. The temperature response of $23 \mathrm{~J}$ CA flat specimens with $45 \mathrm{~mm}$ uniform width is presented in the Fig. 5 for a comparison of specimen shape effect - which suggests that the temperature rise in hour glass specimen is much lower compared to flat specimen. This could be due to the combined effect of average temperature that was measured over the window of 25 $\mathrm{mm} \times 35 \mathrm{~mm}$ and localized damage present in the hour glass specimen.

Amongst the specimens tested after impact with higher impact energies ( $35 \mathrm{~J}$ and $51 \mathrm{~J}$ ), the residual strength of $35 \mathrm{~J}$ Hi-Lo was comparatively high as seen in Fig. 2 (a) (as well as in Tab. 1); the temperature rise during tensile pull out had a distinct peak as seen in Fig. 6. For other specimens, the impact and post-impact fatigue damage is severe and is distributed over the specimen gage section and hence the temperature change at the onset of tensile failure (ply brakeage) is negligible. Fig. 7 presents the typical temperature-time response and corresponding load-time response for $23 \mathrm{~J}$ and $35 \mathrm{~J}$ impacted specimens. The temperature rise is due to the energy dissipation during the fiber breakage and fiber-matrix debonding during tensile pull-out, and this indirectly indicates the severity of the damage present in the specimen. Further, the temperature rise is proportional to the load drop at the onset of failure. 


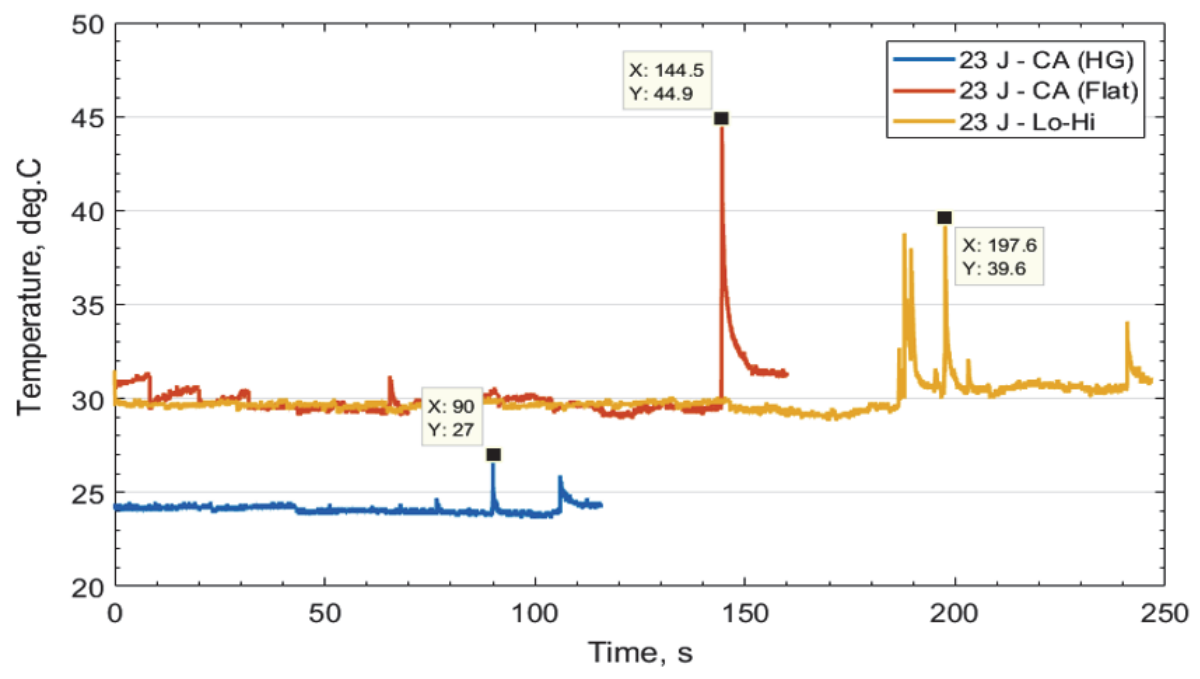

Figure 5: The temperature response curves for $23 \mathrm{~J}$ impacted fatigue loaded specimens.

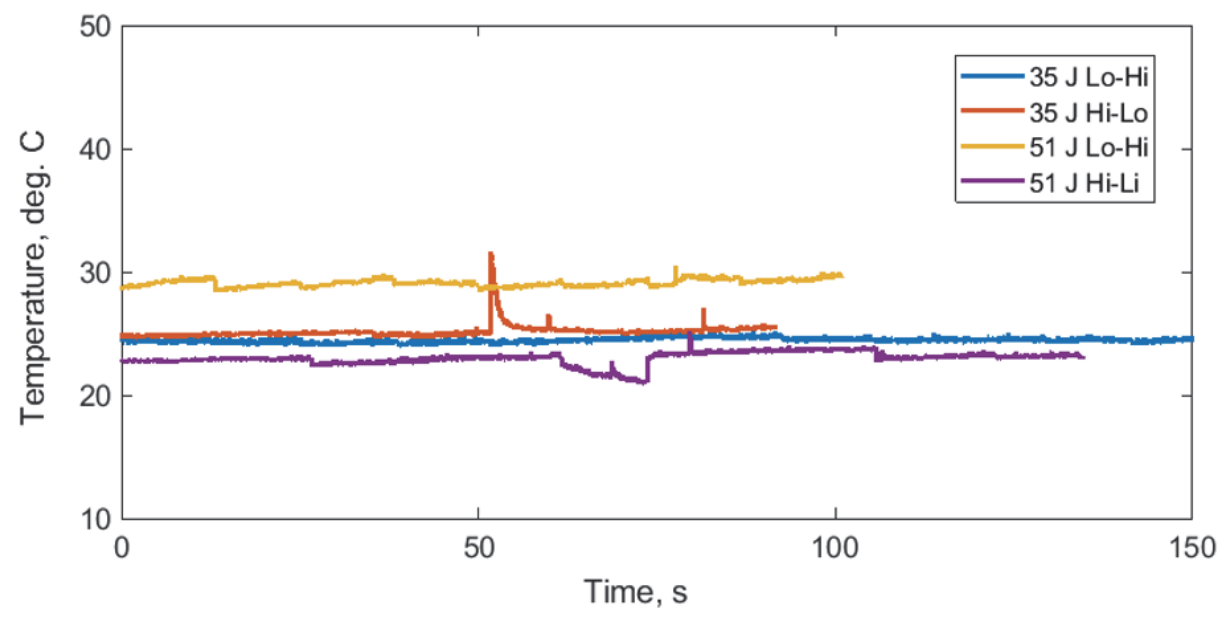

Figure 6: The temperature response curves for $35 \mathrm{~J}$ and $51 \mathrm{~J}$ impacted fatigue loaded specimens.

\section{Infrared Thermography - Active Thermography}

The cooling response curves for the post- impact, post fatigue CFRP specimens with impacted surface facing camera (ISF) and impacted surface at back (ISB) with transmission (HB) and reflection (HF) mode were obtained by the active thermography technique. Tab. 2 presents the details of end state damage condition of the hour glass specimens in terms of residual strength, loss in stiffness and damage volume quantified by X-ray Computed Tomography technique. The loss in stiffness due to impact and post-impact fatigue loading was estimated from the end cycle stiffness and is compared with the pristine specimen stiffness. The intra-laminar damage which causes stiffness degradation in the specimens was quantified in terms of damage volume through the digital image processing of the planar $2 \mathrm{D}$ image slices that were obtained from the 3D X-ray CT; the damage volume was observed to correlate well with the loss in specimen stiffness. Four such successive images from the impacted surface for the $35 \mathrm{~J} \mathrm{Hi-Lo} \mathrm{specimens} \mathrm{from} \mathrm{the} \mathrm{least} \mathrm{width} \mathrm{section} \mathrm{of} \mathrm{hour}$ glass specimen are presented in Fig. 8(a). The distance between successive 2D image slices was chosen as $0.45 \mathrm{~mm}$, which nearly coincides with each layer thickness of the laminate.

The cooling response of some of these tested specimens keeping the impact surface at front (ISF) with heating at the back (HB) or heating at the front (HF) configuration is shown in Fig. 8(b). Also shown in the same figure is the cooling response of pristine specimen. The temperature response at the minimum width region (segment A2) is considered for this purpose, as this is the region where the intra-laminar damage is concentrated. Since the specimens were heated to different temperatures for both the transmission and reflection mode, the cooling response was normalized with reference to the initial temperature at the start of cooling and the same is plotted as a function of time. This helps to understand the 
cooling response better. It is observed that in the case of transmission mode i.e. heating from back (HB), the peak normalized temperature $(\mathrm{Tp})$ and the time lag $(\Delta \mathrm{t})$ for reaching the peak temperature (on the surface facing the IR camera) from which point the cooling response starts is proportional to the extent of impact-fatigue damage that is present in the specimen. The pristine samples too showed a small time lag, which was proportional to the thickness of the specimen. The increase in peak temperature and the time delay to reach the peak temperature prior to start of cooling could be due to the presence of different modes of failures within the specimen and due to the presence of air gap which has a different thermal diffusivity that is trapped between the different layers of the laminate. In the case of reflective mode (HF) of active thermography, the fast exponential cooling rate in the initial part of the temperature response curve (say observed within initial 80 seconds) provides an alternate method to assess the extent of damage present in the specimen. Upon comparing the temperature response curves of post-impact fatigue loaded specimens with that of pristine specimen in both ISF HB and ISF HF configurations, the shift in the cooling response curves from that of the pristine can be seen, but no correlation can be made with the extent of damage.
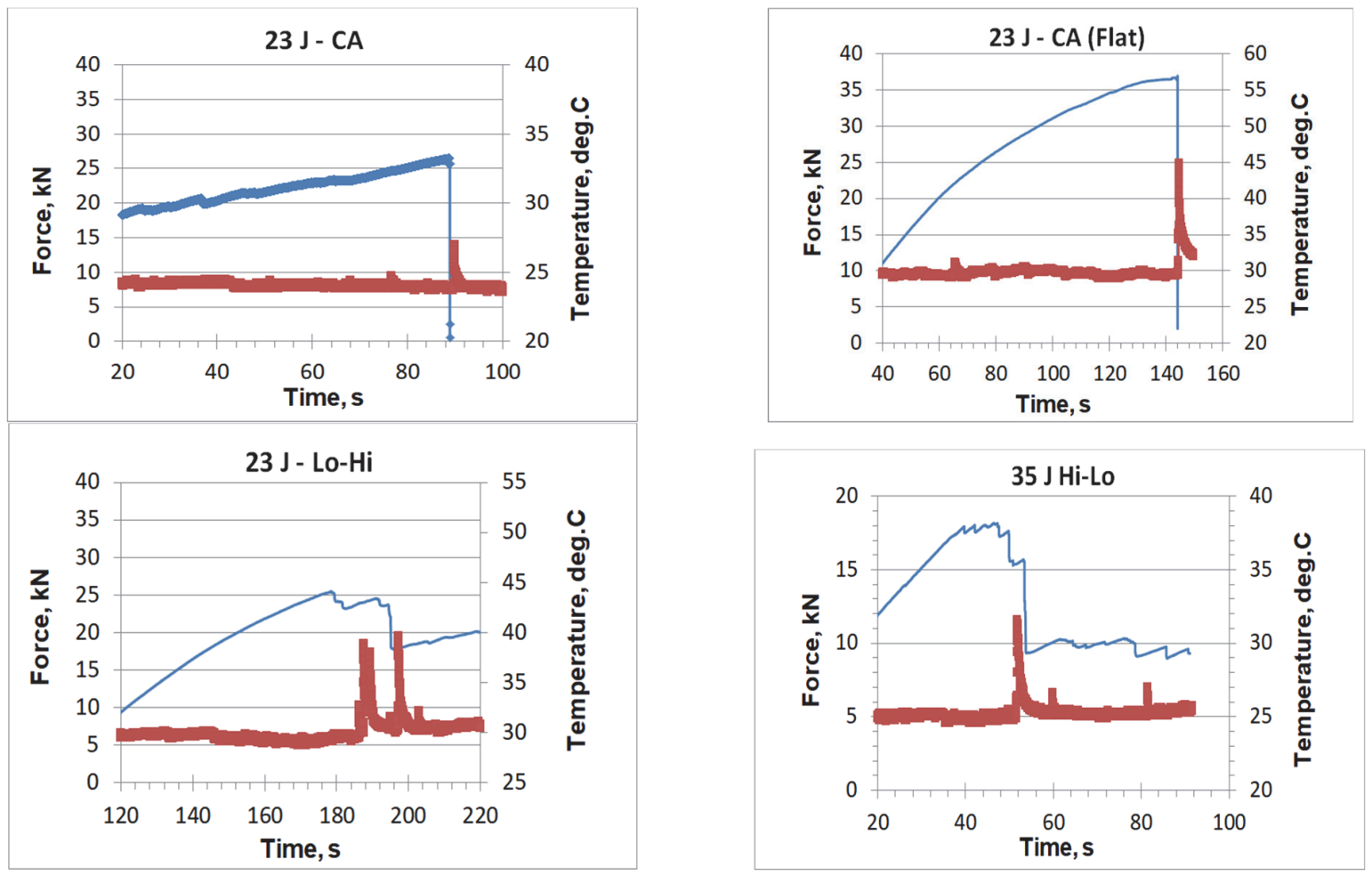

Figure 7: The combined Force vs. time and Temperature vs. time plots (blue line) for the post-impact post-fatigue specimens (the temperature response at the middle region (A2) (shown by dark red color) is plotted.

Fig. 9(a) presents the cooling response of impact damaged specimens with the impacted surface on the rear side of the IR camera. Similar to the previous case of ISF, the cooling response shows a time delay to achieve the peak normalized temperature in transmission mode (HB). Fig. 9(b) shows the histogram of damage volume estimated through image analysis of X-ray CT images for the three specimens considered for this analysis. Upon plotting the peak normalized temperature $(\mathrm{Tp})$ as well as the time lag $(\Delta \mathrm{t})$ for reaching the peak temperature versus the damage volume, a good correlation was observed as shown in Fig. 9(c) for the heating from back (ISB-HB) configuration. The large shift in peak temperature and time delay observed in the case of $51 \mathrm{~J} \mathrm{Lo-Hi} \mathrm{may} \mathrm{be} \mathrm{due} \mathrm{to} \mathrm{the} \mathrm{presence} \mathrm{of} \mathrm{major} \mathrm{de-lamination} \mathrm{in} \mathrm{the}$ specimens. Such a clear distinction in cooling response cannot be easily tracked from ISB-HF configuration data. From the above, it can be said that for the qualitative analysis of post-impact fatigue damage in composites the ISB configuration is preferred over ISF and the HB configuration may be chosen over HF as it gives more accurate results. Further, the use of active thermography with impact surface at back (ISB) and transmission mode (HB) of heating provides a good understanding of the damage state of the specimen, though more work is required to quantify the damage that exists across multiple layers of laminate. 


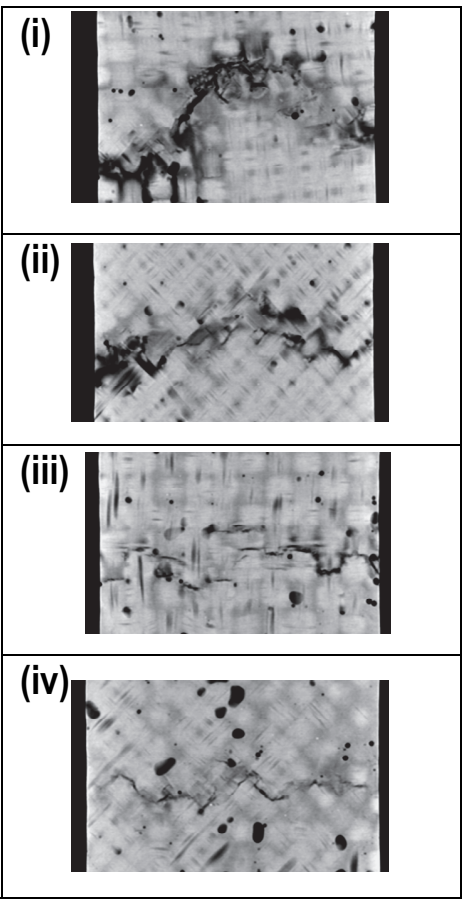

(a)

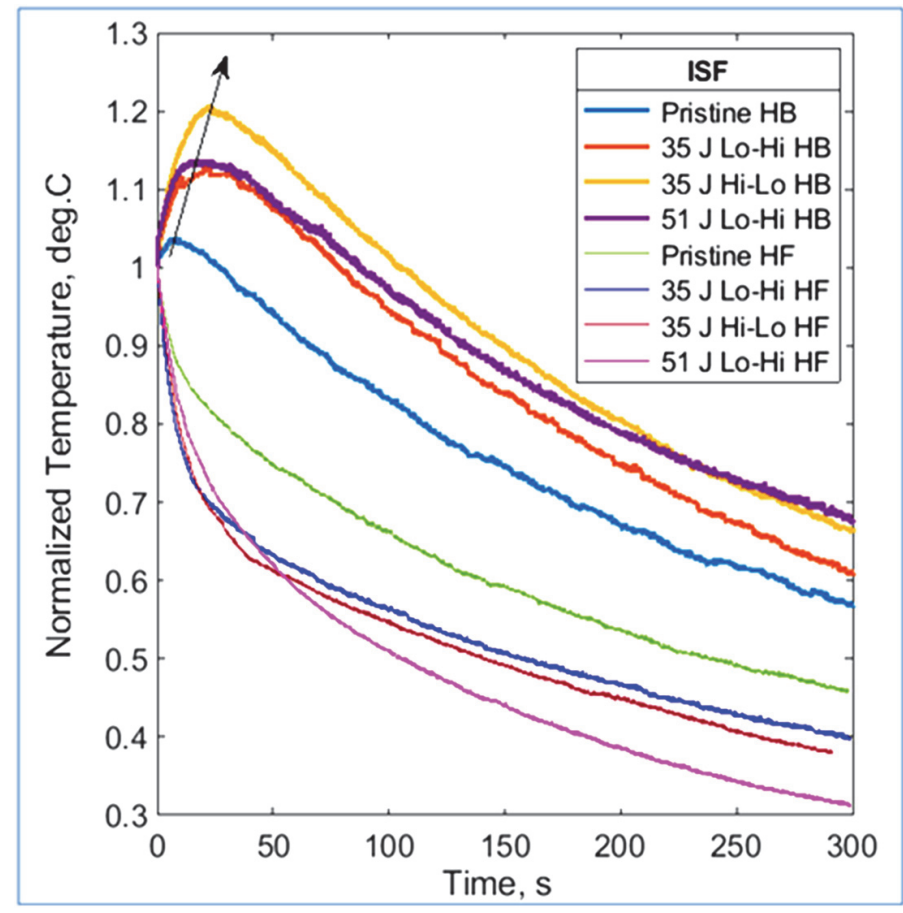

(b)

Figure 8: (a) 2D planar section images showing intra-laminar impact-fatigue damage of $35 \mathrm{~J} \mathrm{Hi-Lo} \mathrm{;} \mathrm{(b)} \mathrm{The} \mathrm{cooling} \mathrm{response} \mathrm{of} \mathrm{the}$ post-impact fatigue tested specimens with impacted surface at the front (ISF).

\section{CONCLUSIONS}

$\mathrm{T}$ he whole field IR thermographic NDT technique was used for the damage analyses of post-impacted fatigue loaded CFRP laminates. Heat dissipation at the onset of ply breakage and failure of the post-impact, post-fatigue specimens was captured by the IR camera by the passive thermography technique. The thermo-elastic response for pristine specimen could be tracked, but not for impact damaged specimens. It is observed that the temperature profile corresponds to the load drops during tensile pull out experiments. The location of corresponding fiber breakage/ fiber matrix debonding and the non-homogeneous spread of damage across the specimen during tensile failure can be visualized from thermograms. Thus, IR thermography can be employed as a meaningful technique for the qualitative understanding of damage progression during static residual tensile tests.

The active IR thermograhy was used to understand the end state damage condition of the post-impacted fatigue loaded specimens. The cooling responses obtained for different specimens from the four different configuration of experimental set up were compared with respective damage state of the specimens quantified through the X-ray CT scan image processing. The extent of impact, fatigue damage in the specimens was found to be reflected in the temperature-time profile for all the four configurations. The cooling response curves obtained from transmission mode with impact surface at the back (ISB HB) configuration correlates well with the damage estimated from X-ray Computed Tomography. Hence it can be concluded that both the active and passive thermography can be employed for the damage progression analysis of CFRP specimens.

\section{ACKNOWLEDGMENT}

$\mathrm{T}$

he first author acknowledges the discussions and support received from Prof. Michele Carboni and his colleagues at the Department of Mechanical Engineering, Politecnico Di Milano, Italy. The authors thank Prof. Krishnan Balasubramanian, C-NDE, IIT Madras for support in CT imaging. 


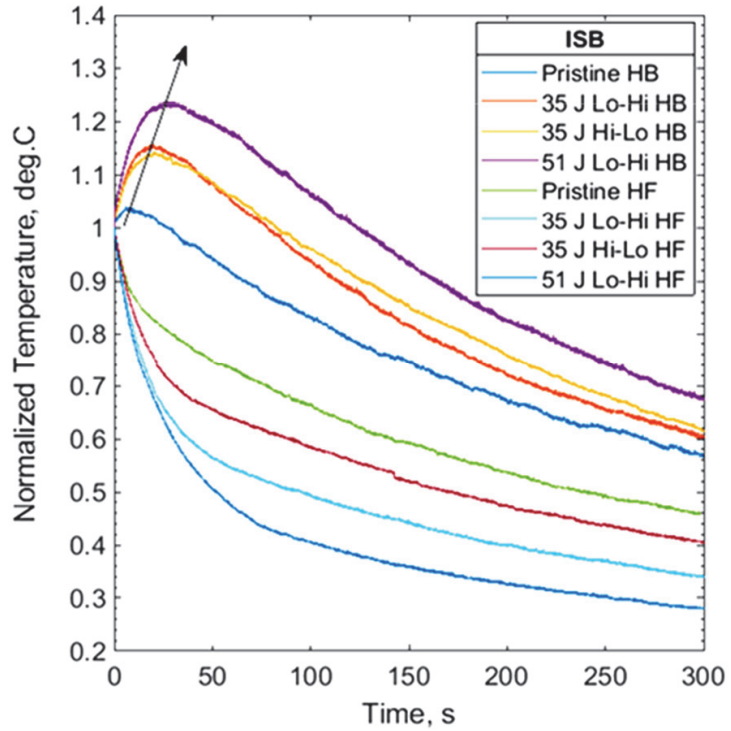

(a)

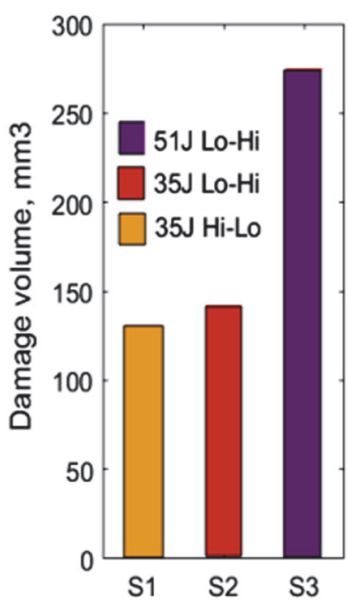

(b)

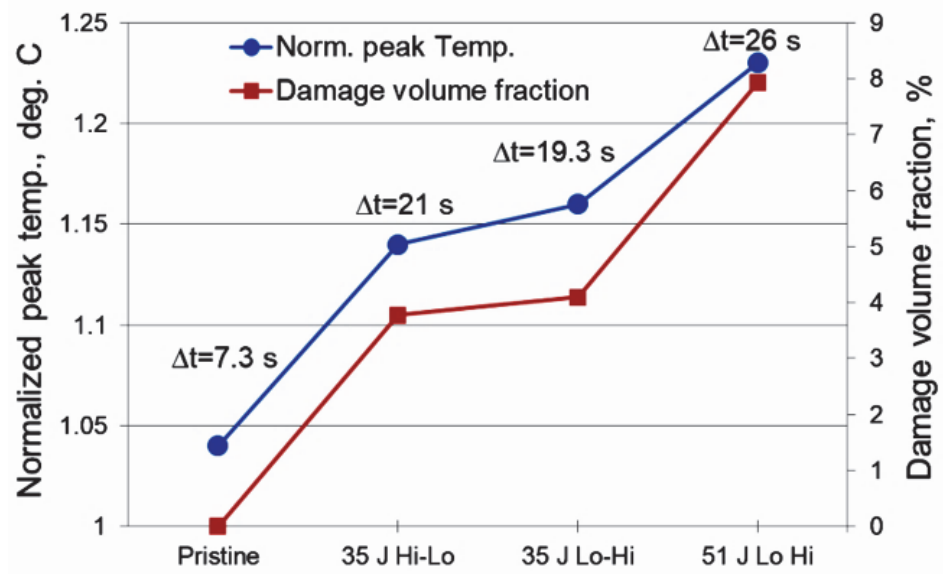

(c)

Figure 9: (a) Cooling response of the tested specimens with impacted surface at back (ISB); (b) the quantified damage in the specimens; (c) The normalized peak temperature during active IRT for the CFRP specimens is given against the corresponding damage volume fraction (ISB HB configuration).

\section{REFERENCES}

[1] Meola, C., Boccardi, S., Carlomagno, G.M., Boffa, N.D., Monaco, E., Ricci, F., (2015). Nondestructive evaluation of carbon fibre reinforced composites with infrared thermography and ultrasonics, Composite Structures, 134, pp. 845853. DOI: $10.1016 /$ j.compstruct.2015.08.119

[2] Katunin, A., Dragan, K., Dziendzikowski, M. (2015). Damage identification in aircraft composite structures: A case study using various non-destructive testing techniques, Composite Structures, 127, pp. 1-9. DOI: $10.1016 /$ j.compstruct.2015.02.080.

[3] Li, Y., Zhang, W., Yang, Z.-w., Zhang, J.-y., Tao, S.-j. (2016). Low-velocity impact damage characterization of carbon fiber reinforced polymer (CFRP) using infrared thermography, Infrared Physics \& Technology 76, pp. 91-102. DOI: 10.1016/j.infrared.2016.01.019

[4] Harizi, W., Chaki, S., Bourse, G., Ourak, M. (2014). Mechanical damage assessment of Polymer-Matrix Composites using active infrared thermography, Composites: Part B, 66, pp. 204-209. DOI: 10.1016/j.compositesb.2014.05.017. 
[5] Montesano, J., Fawaz, Z., Bougherara, H. (2013). Use of infrared thermography to investigate the fatigue behavior of a carbon fiber reinforced polymer composite, Composite Structures, 97, pp. 76-83.

DOI: $10.1016 /$ j.compstruct.2012.09.046

[6] Jespersen, K. M., Zangenberg, J., Lowe, T., Withers, P. J., Mikkelsen, L. P. (2016). Fatigue damage assessment of unidirectional non-crimp fabric reinforced polyester composite using X-ray computed tomography, Composites Science and Technology, 136, pp. 94-103. DOI: 10.1016/j.compscitech.2016.10.006

[7] Little, J. E., Yuan, X., Jones, M. I. (2012). Characterisation of voids in fibre reinforced composite materials, NDT\&E International, 46, pp. 122-127. DOI: 10.1016/j.ndteint.2011.11.011.

[8] Lambert, J., Chambers, A.R., Sinclair, I., Spearing, S.M., (2012). 3D damage characterisation and the role of voids in the fatigue of wind turbine blade materials. Composites Science and Technology, 72, pp. 337-343. DOI: 10.1016/j.compscitech.2011.11.023

[9] Mitchenko, E. I., Prakash, R. V., Sunder, R., (1995). Fatigue Crack growth under an equivalent FALSTAFF spectrum, Fatigue Fract. Eng.Mater. Struct.; 18(5), pp. 583-595.

[10] Prakash, R.V., Sunder, R., Mitchenko, E. I., (1996). A Study of naturally initiating notch root fatigue cracks under spectrum loading, ASTM STP 1292, American Society for Testing and Materials, pp. 136-160.

[11] Prakash, R. V., John, M., Sudevan, D., Gianneo, A, and Carboni, M., (2017). Fatigue Studies on Impacted and Unimpacted CFRP Laminates, ASTM STP 1598 on Fatigue and Fracture Test Planning, Test Data Acquisitions and Analysis, pp. 94-118. DOI: 10.1520/STP159820160094,

[12] Prakash, R. V., John, M. and Carboni, M., (2018) A Multiple-loading single-sample exploratory method of estimating damage in polymer composite materials through analysis of X-ray tomography images, ASME PVP proceedings, 6B, DOI:10.1115/PVP2018-84411.

[13] Mohamed Muneer, K. M., Prakash, R. V. and Balasubramaniam, K. (2009). Thermomechanical Studies in Glass/Epoxy Composite Specimen during Tensile Loading, World Academy of Science, Engineering and Technology International Journal of Mechanical and Mechatronics Engineering 3(8). 